\title{
Characteristics of tuberculosis patients in the integrated tuberculosis control model in Chongqing, China: a retrospective study
}

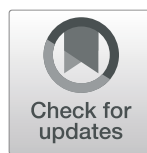

Liwen Zhang ${ }^{1,2+}$, Wei Xing ${ }^{1 \dagger}$, Jiani Zhou ${ }^{1 \dagger}$, Rui Zhang ${ }^{1}$, Yong Cheng ${ }^{1}$, Jin Li ${ }^{1}$, Geng Wang ${ }^{1}$, Shili Liu ${ }^{1}$ and Ying $\mathrm{Li}^{i^{*}}$ (D)

\begin{abstract}
Background: China ranks second in the world in terms of numbers of tuberculosis (TB) cases and is one of the top three countries with the largest number of multidrug-resistant and rifampicin-resistant TB (MDR/RR-TB). It also has high mortality and low cure rates of human immunodeficiency virus (HIV)-positive TB patients. This study aimed to analyse, under the integrated TB control model, the characteristics of TB patients seeking healthcare in the largest designated TB hospital in Chongqing.

Methods: This was a retrospective study of TB registers in a health facility. Record data of 1827 TB patients who had attended the Chongqing Public Health Medical Center (CPHMC) from 1 January to 31 December 2018 were included. The Statistical Package for Social Science (SPSS 18.0; IBM Corporation, Armonk, NY, USA) was used to analyse the data. Counting data were compared using the chi-square test or Fisher' $s$ exact test. Among the results of the univariate analysis, the variables with statistical significance were included in the binomial stepwise logistic regression, with odds ratio and 95\% confidence interval calculated. A two-tailed probability level of $P<0.05$ was considered statistically significant.
\end{abstract}

Results: The majority of registered patients were men (1197), of Han ethnicity (1670), aged 21-60 years (1331), farmer/unemployed (1075), and living in county/district (1207). Approximately $24.9 \%$ of patients (455/1827) contracted DR-TB, 6\% (110/1827) were co-infected with HIV, and 41.0\% (749/1827) had drug-related hepatotoxicity. Among those patients, DR-TB was more likely to develop among farmers who received retreatment and had drugrelated hepatotoxicity $(P<0.05)$. Women who received retreatment and lived in county/district were less likely to be HIV positive $(P<0.05)$. Compared with farmers, patients who were unemployed were more likely to be HIV positive, and those aged $21-60$ years had a higher risk of being tested as HIV positive $(P<0.05)$.

Conclusion: Farmers who received retreatment and had drug-related hepatotoxicity are more susceptible to DR-TB; young unemployed men have a higher risk of contracting HIV-positive TB. The demographic and clinical characteristics of TB patients should be taken into consideration in DR-TB and HIV-positive TB screening in the future.

Keywords: Tuberculosis, Drug-resistant tuberculosis, HIV-positive tuberculosis, Retreatment

\footnotetext{
* Correspondence: lilyliying2012@163.com

†Liwen Zhang, Wei Xing and Jiani Zhou contributed equally to this work. 'Department of Social Medicine and Health Service Management, Army

Medical University (Third Military Medical University), No.30 Gaotanyan Road, Shapingba District, Chongqing 400038, China

Full list of author information is available at the end of the article
}

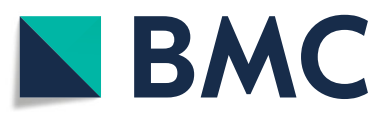

(c) The Author(s). 2020 Open Access This article is licensed under a Creative Commons Attribution 4.0 International License, which permits use, sharing, adaptation, distribution and reproduction in any medium or format, as long as you give appropriate credit to the original author(s) and the source, provide a link to the Creative Commons licence, and indicate if changes were made. The images or other third party material in this article are included in the article's Creative Commons licence, unless indicated otherwise in a credit line to the material. If material is not included in the article's Creative Commons licence and your intended use is not permitted by statutory regulation or exceeds the permitted use, you will need to obtain permission directly from the copyright holder. To view a copy of this licence, visit http://creativecommons.org/licenses/by/4.0/ The Creative Commons Public Domain Dedication waiver (http://creativecommons.org/publicdomain/zero/1.0/) applies to the data made available in this article, unless otherwise stated in a credit line to the data. 


\section{Background}

Tuberculosis (TB) is one of the top ten causes of death worldwide and is the leading cause of infectious diseases [1]. According to the World Health Organization (WHO)'s Global TB Report 2019, there were 10.0 (9.011,1 ) million new cases of TB, and $3.4 \%$ of new cases and $18 \%$ of previously treated cases developed multidrug-resistant TB (MDR-TB) or rifampicin (RFP)resistant TB (RR/TB) in 2018 [1]. Drug-resistant TB (DR-TB) and TB/human immunodeficiency virus (HIV) co-infection are the challenges in controlling TB (endeavours) worldwide. TB killed 251,000 HIV-positive people globally in 2018, although the number of $\mathrm{TB}$ deaths among HIV-positive people has fallen from 620 , 000 in 2000 to 251,000 in 2018, a decrease of 60, and $8.6 \%$ of TB patients are living with HIV [1]. The latest treatment success rates were $85 \%$ for drug-sensitive TB, $75 \%$ for $\mathrm{HIV}$-associated $\mathrm{TB}$, and $56 \%$ for MDR/RR-TB [1]. In many situations, patients not only had TB/DRTB, but also HIV and other comorbid conditions and complications, which made co-treatment for TB/DR-TB and other diseases more complicated and challenging [2]. It was previously proven that HIV-positive patients are vulnerable to DR-TB, and DR-TB is often associated with higher mortality rates in patients living with HIV $[3,4]$. A higher mortality rate was observed in HIVpositive TB patients [5], and TB patients co-infected with HIV were more likely to develop extra-pulmonary disease [6,7]. Furthermore, hepatotoxicity is one of the most common $\mathrm{TB}$ complications caused by first-line drugs (isoniazid [INH], RFP, and pyrazinamide), as these drugs are highly associated with hepatotoxicity [4].

China is burdened with the second largest number of TB and MDR-TB cases with an estimated 886,000 TB patients (including TB/HIV co-infection), 66,000 MDR/ RR-TB patients, and $2400 \mathrm{~TB} / \mathrm{HIV}$ co-infection patients in 2018 [1]. According to the report of the fifth national TB epidemic research in 2010, Chinese TB prevalence is much higher in the western region compared with that in the eastern and central regions with an active TB rate of 695 per 100,000 persons, while those in the eastern and central regions are 291 per 100,000 and 463 per $100,000[8]$.

The Chongqing municipality is one of four municipalities directly under the control of the Central Government of China, which is located in southwest China [8]. With over 30 million residents, Chongqing has a high proportion of migrant workers and the highest TB prevalence compared with the other three municipalities $[9,10]$. Recently, Chongqing has begun to pay more attention to TB control and has implemented a national TB control programme with great progress [11]. However, the fifth national TB epidemic survey in 2010 indicates that Chongqing's active TB prevalence rate $(>15$ years) and average reported prevalence were both higher than the national average rates [12-14]. The national survey in 2015 indicated that the incidence of TB in Chongqing was $75 / 100,000$, ranking tenth among the top 10 in China [15]. Therefore, TB control in Chongqing faced many challenges, such as the prevalence of MDR-TB and TB/HIV co-infection. Since the implementation of the 12th 5 Year Plan of the National TB Program in 2011, China's TB control model has transformed from the "Center for Disease Control and Prevention (CDC) model" to the "integrated model" in most regions [16]. In the integrated model, the $C D C$ is responsible for the planning, supervision, and health education of TB control. Designated hospitals are responsible for $\mathrm{TB}$ diagnosis and treatment. Primary healthcare facilities are responsible for case management and patient referrals [16]. In the integrated model, TB was diagnosed according to the guidelines of TB control issued in 2017 [17], and the treatment of TB referred to the Guidelines for implementing the national TB control programme in China (2008) [18]. Chongqing has also implemented the integrated model so that TB patients can receive therapy in designated hospitals since 2016. To better understand the progress made in Chongqing's TB control as part of the integrated model, it is essential to reanalyse TB epidemiology in Chongqing. This study aimed to understand the characteristics of TB epidemiology in Chongqing, particularly among DR-TB and TB/ HIV co-infection patients. It also aimed to identify the population at higher risk of DR-TB and HIV-positive TB to provide evidence that can serve as a basis for making responsive strategies to end the spread of $\mathrm{TB}$ in Chongqing.

\section{Methods}

\section{Setting and participants}

We performed a retrospective study using the registered data collected. The Chongqing Public Health Medical Center (CPHMC) is the biggest tertiary hospital with Grade A level of prevention and treatment for infectious diseases in Chongqing. In addition, CPHMC, as the Medical Quality Control Center of TB, HIV, and respiratory infectious diseases, is the officially designated hospital for diagnosis and treatment of TB, MDR-TB, and HIV in Chongqing [19]. Therefore, we chose the recorded data from the TB reporting system in CPHMC to represent TB patients in Chongqing, China. The TB reporting system includes the following information: individual data on TB patients; TB diagnosis, treatments, and outcome; quarterly National TB Program activity reports from TB dispensaries at all levels; and annual reports on funding for TB control activities [20]. TB cases were diagnosed based on the Chinese clinical guidelines for $\mathrm{TB}$ diagnosis and treatment in CPHMC. CPHMC 
reports all notified TB patients to the China Information System for Disease Control and Prevention (CIS-DCP). A total of 1827 patients with pulmonary TB attended CPHMC to receive TB treatment from 1 January to 31 December 2018 and were included in our study.

\section{Data sources and statistical analyses}

The standard form was used to collect the data of each TB patient during the study period. The record system in CPHMC includes age, gender, occupation, living region, ethnicity, symptoms, and drug-related hepatotoxicity, viral hepatitis, TB type, and HIV infection. Observational variables in this study included demographic and clinical characteristics of the patients and factors associated with DR-TB and TB/HIV co-infection. Several definitions related to TB were used in this study. DR-TB consists of MR-TB, MDR-TB, XDR-TB, PDRTB, RR-TB, and Hr-TB in our study. Mono-resistant TB (MR-TB) refers to Mycobacterium tuberculosis strains with resistance to one first-line anti-TB drug [5]. MDR$\mathrm{TB}$ is defined as TB that is simultaneously resistant to the two most powerful anti-TB drugs, RFP and INH, with or without resistance to other first-line drugs and requires treatment with second-line drugs [1]. XDR-TB is defined as MDR-TB plus resistance to at least one drug in both fluoroquinolones and second-line injectable agents (amikacin, capreomycin, or kanamycin), which are the two most important classes of medicines in MDR-TB treatment [21]. Poly-drug-resistance (PDR-TB) refers to resistance to more than one first-line anti-TB drug, other than isoniazid (INH) and RFP [22]. RR-TB is considered susceptible to INH, resistant to INH, or resistant to other first-line TB drugs or second-line TB drugs that also require treatment with a second-line regimen [14]. INHresistant TB (Hr-TB) refers to $M$. tuberculosis strains with resistance to INH and susceptibility to RFP confirmed in vitro [21]. The results of this study were reported following the Strengthening the Reporting of Observational studies in Epidemiology (STROBE) statement for reports of observational studies.

All patients' registration system information were collected from the Chongqing Public Health Medical Center. The Statistical Package for Social Science (SPSS 18.0; IBM Corporation, Armonk, NY, USA) was used to analyse the data. Counting data were compared using the chi-square test or Fisher' s exact test to explore the differences in demographic and clinical characteristics among DR-TB and HIV-positive TB patients. Based on the results of univariate analysis, the variables with statistical significance were included in the binomial stepwise logistic regression, and odds ratio and its corresponding 95\% confidence interval were calculated. A two-tailed probability level of $P<0.05$ was considered significant.

\section{Results}

\section{Patients' characteristics}

The demographic and clinical characteristics of patients are illustrated in Table 1. A total of 1827 patients were included in our study, and majority of them $(65.5 \%, n=$ 1197) were men. Among them, $72.9 \%(n=1331)$ were aged $21-60$ years, $91.4 \%(n=1670)$ were of Han ethnicity, and $66.1 \%(n=1207)$ were from the county/district of Chongqing. A total of $565(30.90 \%)$ patients were farmers, 510 (27.9\%) were unemployed, 257 (14.1\%) were currently non-working, and 174(9.5\%) were students. Approximately $22.9 \% \quad(n=418)$ of the patients had retreatment of TB and 455 (24.90\%) had DR-TB. Notably, $87.03 \%(n=396)$ DR-TB of the patients had MDRTB. In addition, 110 (6\%) TB patients were co-infected with HIV.

\section{Factors associated with DR-TB and TB/HIV co-infection}

Results of $X^{2}$ tests (Table 2) indicated that patients of Han ethnicity were less likely to have DR-TB compared with other ethnicities $(23.90 \%$ vs. $35.70 \%, P=0.002)$. Housekeepers were more likely to have DR-TB than other professions $(P<0.001)$. Patients who lived in suburban counties/districts were more likely to have DR-TB (27.10\% vs. $20.60 \%, P=0.001)$ than those living in central urban areas. Patients aged between 21 and 60 years had a higher risk of having DR-TB than those aged less than 21 years and more than 60 years $(P=0.010)$. Patients in retreatment $(95.20 \%$ vs. $4.00 \%, P<0.001)$ and with drug-related hepatotoxicity $(43.70 \%$ vs. $11.90 \%, P<$ 0.001 ) were more likely to have DR-TB. However, HIVpositive TB patients were less likely to have DR-TB than HIV-negative TB patients $(8.20 \%$ vs. $26.00 \%, P<0.001)$. No differences were observed in sex, symptoms (excluded revisit patients as they had no initial symptoms based on their clinical records), and viral hepatitis between drug-sensitive TB patients and DR-TB patients $(P>0.05)$.

As Table 2 shows, male TB patients were more likely to be HIV positive compared with women $(7.30 \%$ vs. $3.70 \%, P=0.002)$. Patients who were unemployed were more likely to be HIV positive $(P<0.001)$ than those who had jobs. Patients living in central urban areas were more likely to be HIV positive than those living in county/district $(8.20 \%$ vs. $4.90 \%, P=0.007)$. Patients aged 21-60 years had a much higher risk of being HIV positive than those aged less than 21 years and more than 60 years $(P=0.005)$. However, patients who received retreatment were less likely to be HIV positive than those who did not receive retreatment $(1.90 \%$ vs. $7.20 \%$, $P<0.001)$. No differences were observed among different ethnicities, existence of drug-related hepatotoxicity, and viral hepatitis between HIV-negative patients and HIVpositive patients $(P>0.05)$. 
Table 1 Demographic and clinical characteristics of TB patients

\begin{tabular}{|c|c|c|c|}
\hline Characteristics & Categories & Number (N) & Percent (\%) \\
\hline \multirow[t]{2}{*}{ Gender $(N=1827)$} & Male & 1197 & 65.50 \\
\hline & Female & 630 & 34.50 \\
\hline \multirow[t]{2}{*}{ Ethnicity $(N=1827)$} & Han & 1670 & 91.40 \\
\hline & Others & 157 & 8.60 \\
\hline \multirow[t]{7}{*}{ Occupation $(N=1826)$} & Farmer & 565 & 30.90 \\
\hline & Unemployed & 510 & 27.90 \\
\hline & Currently non-working & 257 & 14.10 \\
\hline & Student & 174 & 9.50 \\
\hline & Housekeeping & 101 & 5.50 \\
\hline & Manual worker & 68 & 3.70 \\
\hline & Others & 151 & 8.30 \\
\hline \multirow[t]{2}{*}{ Living region $(N=1827)$} & Central urban & 620 & 33.90 \\
\hline & County/district & 1207 & 66.10 \\
\hline \multirow[t]{4}{*}{$\operatorname{Age}(N=1827)$} & $\leq 20$ & 224 & 12.30 \\
\hline & $21-40$ & 692 & 37.90 \\
\hline & $41-60$ & 639 & 35.00 \\
\hline & $\geq 61$ & 272 & 14.90 \\
\hline \multirow[t]{2}{*}{ Symptoms $(N=915)$} & Typical symptoms & 464 & 50.70 \\
\hline & Others & 451 & 49.30 \\
\hline \multirow[t]{2}{*}{ Retreatment $(N=1827)$} & Yes & 418 & 22.90 \\
\hline & No & 1409 & 77.10 \\
\hline \multirow[t]{2}{*}{ Drug-related hepatotoxicity $(N=1827)$} & Yes & 749 & 41.00 \\
\hline & No & 1078 & 59.00 \\
\hline \multirow[t]{2}{*}{ Viral hepatitis $(N=1827)$} & Yes & 44 & 2.40 \\
\hline & No & 1783 & 97.60 \\
\hline \multirow[t]{2}{*}{ AIDS/HIV $(N=1827)$} & Yes & 110 & 6.00 \\
\hline & No & 1717 & 94.00 \\
\hline \multirow[t]{6}{*}{$\mathrm{DR}-\mathrm{TB}(N=455)$} & MDR-TB & 396 & 87.03 \\
\hline & MR-TB & 18 & 4.00 \\
\hline & XDR-TB & 16 & 3.50 \\
\hline & PDR-TB & 13 & 2.86 \\
\hline & $\mathrm{Hr}-\mathrm{TB}$ & 2 & 0.44 \\
\hline & RR-TB & 10 & 2.2 \\
\hline
\end{tabular}

Notes: Missing data were excluded

Multivariate analysis of factors associated with DR-TB and TB/HIV co-infection is presented in Table 3. The assignment of variables is shown in Additional file 1 . The binomial stepwise logistic regression is shown in Table 3. TB type and HIV infectious status were the dependent variables $(\mathrm{Y})$. Gender, ethnicity, occupation, living region, age, retreatment, drug-related hepatotoxicity, and HIV were the independent variables (X). Results indicated that patients who received retreatment and had drug-related hepatotoxicity were more likely to have DR-TB. However, compared with farmers, patients who worked in other occupations were less likely to have DR-TB. The results showed that patients who received retreatment and lived in county/district were less likely to be HIV positive. Female patients were less likely to be HIV/AIDS positive than male patients. However, compared with farmers, patients who were unemployed were more likely to be HIV-positive, and patients aged 21-60 years had a higher risk of being HIV-positive than those aged less than 21 years and more than 60 years. 
Table 2 Univariate analysis of factors association with DR-TB patients and TB/HIV co-infection

\begin{tabular}{|c|c|c|c|c|c|}
\hline Variables & Categories & $\begin{array}{l}\text { DR-TB } \\
(N=455)\end{array}$ & $P\left(x^{2}\right.$ test $)$ & TB/HIV co-infection $(N=110)$ & $P\left(x^{2}\right.$ test $)$ \\
\hline \multirow[t]{2}{*}{ Gender } & Male & $292(64.2)$ & 0.495 & $87(7.3)$ & $0.002^{*}$ \\
\hline & Female & $163(25.90)$ & & $23(3.70)$ & \\
\hline \multirow[t]{2}{*}{ Ethnicity } & Han & $399(23.90)$ & $0.002^{*}$ & $104(6.20)$ & 0.292 \\
\hline & Others & $56(35.70)$ & & $6(3.80)$ & \\
\hline \multirow[t]{7}{*}{ Occupation } & Farmer & $144(25.50)$ & $<0.001^{*}$ & $32(5.70)$ & $<0.001^{*}$ \\
\hline & Unemployed & $121(23.70)$ & & $56(11.00)$ & \\
\hline & Currently non-working & $70(27.20)$ & & $7(2.70)$ & \\
\hline & Student & $27(15.50)$ & & $2(1.10)$ & \\
\hline & Housekeeping & $44(43.60)$ & & $4(4.00)$ & \\
\hline & Manual worker & $16(23.50)$ & & $3(4.40)$ & \\
\hline & Others & $33(21.90)$ & & $6(4.00)$ & \\
\hline \multirow[t]{2}{*}{ Living region } & Central urban & $128(20.60)$ & $0.001^{*}$ & $51(8.20)$ & $0.007^{*}$ \\
\hline & County/district & $327(27.10)$ & & $59(4.90)$ & \\
\hline \multirow[t]{4}{*}{ Age } & $\leq 20$ & $42(18.700)$ & $0.010^{*}$ & $2(0.90)$ & $0.005^{*}$ \\
\hline & $21-40$ & $186(26.90)$ & & $47(6.80)$ & \\
\hline & $41-60$ & $173(27.10)$ & & $46(7.20)$ & \\
\hline & $\geq 61$ & $54(19.90)$ & & $15(5.50)$ & \\
\hline \multirow[t]{2}{*}{ Retreatment } & Yes & $398(95.20)$ & $<0.001^{*}$ & $8(1.90)$ & $<0.001^{*}$ \\
\hline & No & $57(4.00)$ & & $102(7.20)$ & \\
\hline \multirow[t]{2}{*}{ Drug-related hepatotoxicity } & Yes & $327(43.70)$ & $<0.001^{*}$ & $53(7.10)$ & 0.133 \\
\hline & No & $128(11.90)$ & & $57(5.30)$ & \\
\hline \multirow[t]{2}{*}{ Viral hepatitis } & Yes & $10(22.70)$ & 0.861 & $2(4.50)$ & 1.000 \\
\hline & No & $445(25.00)$ & & $108(6.10)$ & \\
\hline \multirow[t]{2}{*}{ AIDS/HIVS } & Yes & $9(8.20)$ & $<0.001^{*}$ & & \\
\hline & No & $446(26.00)$ & & & \\
\hline \multirow[t]{2}{*}{ Symptoms } & Typical symptoms & $64(13.80)$ & 0.158 & & \\
\hline & Others & $48(10.60)$ & & & \\
\hline
\end{tabular}

Notes: Missing data were excluded. ${ }^{*} P<0.05$.

\section{Discussion}

Our study described the epidemiology of TB patients from CPHMC and evaluated the factors associated with DR-TB and TB/HIV co-infection. Results showed that most TB patients in Chongqing were young and middle aged, which is consistent with the reports in other regions of China [23, 24]. TB cases are more likely to cluster among disadvantaged groups such as the poor, hungry, and ethnic minorities, and most TB patients were farmers, unemployed, and those living in county/ district areas $[1,25]$, which were considered as the populations with relatively poor social economic status, great financial pressure, and non-ideal living conditions [10]. This study consistently found that farmers and unemployed individuals who lived in county/district had higher susceptibility to TB in Chongqing. In 2015, the WHO proposed a core principle, included in the End TB strategy, focusing on social protection in the context of TB, particularly poor and vulnerable populations [26]. Furthermore, the WHO's 2019 Global TB Report also recommended providing social support for vulnerable people, such as transport, food packages, and cashtransfer schemes to avoid catastrophic costs for TB patients and their households [1]. Therefore, the Chongqing $\mathrm{TB}$ prevention and control strategy needs to continue and focus on people with disadvantages in order to address the social determinants of TB.

Students are vulnerable to TB; hence, more TB control and preventive efforts should be made to protect students in schools [4]. TB prevalence among Chinese students $(1520 / 100,000)$ is much higher than that $(459 / 100$, 000) among the general population [27]. Chongqing was one of the regions with the highest TB burden among undergraduate students in China [28]. Several TB outbreaks among students have been recently reported in Chongqing [29-31]. This study also observed that 
Table 3 Binomial stepwise logistic regression analysis for factors associated with DR-TB and TB/HIV co-infection

\begin{tabular}{llll}
\hline Variables & Categories & $\begin{array}{l}\text { DR-TB } \\
\text { OR(95\%Cl) }\end{array}$ & TB/HIV co-infection OR(95\%Cl) \\
\hline Gender & Male & & Reference \\
& Female & Reference & Reference \\
Occupation & Farmer & $0.286,0.765)$ & \\
& Others & $0.340(0.128 .0 .905)$ & $2.013(1.256,3.226)$ \\
Unemployed & Reference \\
Living region & Central urban & & $0.644(0.429,0.968)$ \\
& County/district & Reference \\
Age & $\leq 20$ & $5.817(1.225,27.631)$ \\
Retreatment & $21-40$ & Reference & $5.313(1.093,25.825)$ \\
& $41-60$ & $433.763(248.261,757.874)$ & Reference \\
Drug-related hepatotoxicity & No & Reference & $0.232(0.111,0.484)$ \\
& Yes & $2.676(1.683,4.253)$ & \\
\hline
\end{tabular}

Notes: Only $P<0.05$ presented

almost $10 \%$ of the patients were students in this region. Previous studies have shown that students in this region have poor knowledge of TB [32]. TB programmes in this region need to make more efforts to protect students, particularly those living in school. These efforts include health education and behavioural interventions.

The DR and MDR rates in Chongqing have also increased recently. In 2009, the DR and MDR rates in smear-positive TB patients living in urban areas were 27.62 and $10.50 \%$, respectively, and the MDR rates in new $\mathrm{TB}$ and retreatment $\mathrm{TB}$ patients were 6.99 and $23.68 \%$, respectively [33]. By 2015, the DR and MDR rate in smear-positive TB patients were 35.6 and $23.8 \%$, while the MDR rates of new TB cases and retreatment TB patients were 8.7 and $28.8 \%$, respectively [34]. Approximately $24.90 \%$ of TB patients in our study had DR-TB, while $87.03 \%$ of DR-TB patients had MDR-TB, which indicates that $21.67 \%$ of TB patients had MDR-TB. This study found that the MDR-TB rate was slightly lower than $23.8 \%$, which was the value reported by another study in Chongqing in 2017, and higher than 6.8\%, the value reported in the fifth national TB epidemiological survey in $2010[8,34]$, indicating that the prevalence of DR-TB in Chongqing is serious and cannot be ignored.

Since the first HIV infection was reported in Chongqing, the epidemic has developed particularly fast in recent years. The number of cases reached 32,589 in 2015 [35]. The TB/HIV co-infection rate in Chongqing was $6 \%$ in 2015 , which was much higher than the national average level of $2 \%$ [36]. It is more difficult for TB patients living with HIV to receive TB treatment due to the increasing financial burden, overlapping drug toxic effects, and fragmented care between separated TB and
HIV healthcare programmes; therefore, TB patients coinfected with HIV are more likely to develop DR-TB and have treatment failure $[37,38]$. Some studies pointed out that the risk factors of both DR-TB and HIV could be highly identical, so that many DR-TB patients are coinfected with HIV, which has aggregated the disease burden and increased poor outcomes [39-41]. Therefore, it is essential for healthcare facilities to perform drugsusceptibility tests in every patient with TB and HIV [26].

In addition, $41 \%$ of patients in this hospital in Chongqing developed drug-related hepatotoxicity caused by first-line drugs (INH, RFP, and pyrazinamide). This could affect patients' adherence to treatment and increase the risk of DR-TB. There is an urgent need for more effective anti-TB drugs to shorten the treatment duration, for better healthcare accessibility (both location and capable laboratories), and for faster TB/DR-TB diagnosis to avoid clinical deterioration, death, and transmission [42].

Patients who received retreatment had a higher risk of DR-TB, which was consistent with the results of previous studies $[43,44]$. TB patients with drug-related hepatotoxicity were more likely to have DR-TB, similar to previous observations from other studies [45]. Moreover, farmers were at risk for DR-TB. Farmers had poor accessibility to TB-related healthcare as they lived in remote mountainous areas with poor economic status [46], increasing the risk of developing DR-TB.

Previous studies reported that HIV and DR-TB were the risk factors for each other [39-41, 47]. However, this study found no association between HIV-positive and DR-TB patients among TB patients in Chongqing. This 
result may be explained by the high mortality and default rate reported among TB/HIV co-infection patients $[3,4,48]$. Patients living in the central urban areas of Chongqing had higher risks of acquiring HIV because the prevalence of HIV existed mainly in central urban areas, and the incidence of HIV was high among men who had sex with men living mainly in the central urban areas of Chongqing [49]. Therefore, this might explain why male TB patients had a higher risk of HIV co-infection in our study. Patients aged 21-60 years had higher risks of being HIV positive than those aged less than 21 years and more than 60 years. This may also be attributed to less sexual behaviours and non-intravenous drug use reported by previous studies in recent years [49]. The younger population engaged in more HIV risk activities. In addition, unemployed patients were more likely to have HIV than farmers, as the unemployed population may perform more HIV risk behaviours with more free time and poorer economic conditions. Besides, patients who received retreatment had a lower risk of being HIV positive, which may be due to the high mortality and default rate of HIVpositive TB patients. A low retreatment rate was observed among HIV-positive TB patients.

Our study has some limitations. First, cases registered at other designated hospitals and general hospitals were not included in our data collection, which would result in relatively lesser representative ability of our results. Second, our study population included those who attended CPHM $\mathrm{C}$ for treatment from 1 January to 31 December 2018. Therefore, a few treatment data were missed, such as treatment outcomes, undetected HIV co-infected DR-TB cases, and undetected DR-TB cases. These missing data could influence the results of our data analysis, which may have led to bias in the measurement of the association between HIV-positive TB and DR-TB.

\section{Conclusion}

Young men and socially disadvantaged people, including students, were at higher risk of TB. DR-TB and TB/HIV co-infection remain a challenge in $\mathrm{TB}$ prevention and control in Chongqing. Hence, healthcare services for TB and HIV must be integrated to facilitate early identification and treatment of TB/HIV-positive co-infection patients among the unemployed, young, and urban area TB patients.

\section{Supplementary information}

Supplementary information accompanies this paper at https://doi.org/10. 1186/s12879-020-05304-z.

\section{Additional file 1.}

\section{Abbreviations}

CDC: Center for Disease Control and Prevention: CIS-DCP: China Information System for Disease Control And Prevention; CPHMC: The Chongqing Public
Health Medical Center; DR-TB: Drug-Resistant Tuberculosis; Hr-TB: IsoniazidResistant Tuberculosis; MDR-TB: Multidrug-Resistant Tuberculosis; MRTB: Mono-Resistant Tuberculosis; PDR-TB: Poly-Drug-Resistance Tuberculosis; RR/TB: Rifampicin-Resistant Tuberculosis; STROBE: Strengthening the Reporting of Observational studies in Epidemiology; TB: Tuberculosis; WHO: World Health Organization

\section{Acknowledgements \\ The authors would like to thank the health workers who worked in Chongqing Public Health Medical Center.}

\section{Authors' contributions}

LWZ, WX and YL have designed this survey, JZ, RZ, YC, WX and JL have collected data, LWZ, GW, SL and WX have managed and analyzed data, YL has controlled the quality of data collection and analysis, JZ, RZ and WX have drafted the manuscript. YL has edited the manuscript. All authors have interpreted the results, revised the report and completed the final version.The author(s) read and approved the final manuscript.

\section{Funding}

This project was funded by the National Natural Science Foundation of China (81773489), Social Science and Technology Innovation Subject in Chongqing (cstc2015shmszx120070), the Technology Basic and Advanced Research Projects in Chongqing (cstc2014jcyjA10069). The funders had no role in study design, data collection and analysis, decision to publish, or preparation of the manuscript.

\section{Availability of data and materials}

The datasets generated and/or analysed during the current study are available from the corresponding author on reasonable request.

\section{Ethics approval and consent to participate}

The Ethics Committee of Institutional Review Board of Army Medical University ruled that no formal ethics approval was required in this particular case. The data used in this study was anonymised before its use. And the use of the raw data from this study were approved by the Chongqing Public Health Medical Center.

\section{Consent for publication}

Not applicable.

\section{Competing interests}

The authors declare that they have no competing interests.

\section{Author details}

${ }^{1}$ Department of Social Medicine and Health Service Management, Army Medical University (Third Military Medical University), No.30 Gaotanyan Road, Shapingba District, Chongqing 400038, China. ${ }^{2}$ Chongqing Public Health Medical Center (CPHMC), Chongqing, China.

Received: 22 October 2019 Accepted: 27 July 2020

Published online: 05 August 2020

\section{References}

1. World Health Organization (WHO). Global tuberculosis report. 2019. https:// www.who.int/tb/publications/global_report/en/. Accessed March 2019.

2. Shah M, Reed C. Complications of tuberculosis. Curr Opin Infect Dis. 2014; 27:403-10.

3. World Health Organization (WHO). Companion handbook to the WHO guidelines for the programmatic management of drug-resistant tuberculosis. 2010. http://apps.who.int/iris/bitstream/10665/130918/1/ 9789241548809_eng.pdf. Accessed March 2010.

4. Beauvais S. Management of multi-DR tuberculosis in children: A Field Guide. GHD online. https://www.ghdonline.org/drtb/discussion/practical-guidancefor-pediatric-mdr-tb-management/?ref=profile_detail. Accessed 2012.

5. Barnes PF, Bloch AB, Davidson PT, Snider DE. Tuberculosis in patients with human immunodeficiency virus infection. N Engl J Med. 1991;324:1644-50.

6. Hopewell PC. Impact of human immunodeficiency virus infection on the epidemiology, clinical features, management, and control of tuberculosis. Clin Infect Dis. 1992;15:540-7. 
7. Lucas SB, De Cock KM, Hounnou A, Peacock C, Diomande M, Honde M, et al. Contribution of tuberculosis to slim disease in Africa. BMJ. 1994;308: 1531-3

8. The Fifth National Tuberculosis Epidemiological Sampling Survey Technical Steering Group. The fifth National Tuberculosis Epidemiology Sampling Survey report. Chin J Ant tuberculosis. 2012;34:485-508.

9. Zhou ZW, Tao LH, Hu DY, Li Q, Ma JJ, Yi J. Analysis the epidemiological and trends of pulmonary tuberculosis from 1998 to 2009 in Chongqing and discussion on prevention and control strategies. Mod Prev Med. 2013;40: 201-7.

10. Wang Y. Report of the fifth National Sampling Survey of TB epidemiology. Beijing: Military Medical Science Press; 2011. p. 1-7p.

11. Wu B, Yu Y, Xie W, Liu Y, Zhang Y, Hu D, et al. Epidemiology of tuberculosis in Chongqing, China: a secular trend from 1992 to 2015. Sci Rep. 2017;7:7832.

12. Chinese Center for Disease Control and Prevention. China Tuberculosis Surveillance Report. 2010.

13. Liu Y, Liu J, Jing KH, Chen I, Shen J. Analysis on monitoring results of resistance of anti-tuberculosis drug in Chongqing. Mod Prev Med. 2012;39: 692-4.

14. Duarte R, Lönnroth K, Carvalho C, Lima F, Carvalho AC, Mu Oz-Torrico M, et al. Tuberculosis, social determinants and co-morbidities (including HIV). Pulmonology. 2017;24:115-9.

15. Chen WY, Wei X. Li T, Chen H. analysis of global and Chinese tuberculosis epidemics in 2015. J Tuberc Lung Health. 2016;1:32-3616.

16. Zou GY, Wei XL, Walley JD, Yin J, Sun Q. Factors influencing integration of TB services in general hospitals in two regions of China: a qualitative study. BMC Health Serv Res. 2012;12:21.

17. National Health and Family Planning Commission of the people's Republic of China. Diagnosis for pulmonary tuberculosis. 2017.

18. Department of Disease Control and Department of Medical Administration of Ministry of Health of PRC, Chinese Center for Disease Control and Prevention. Guidelines for implementing the national tuberculosis control program in China. Beijing: Peking Union Medical College Press; 2008.

19. Chongqing Public Health Medical Center : About the center. Available: http://www.cqgwzx.com/column/about/zhongxinjianjie/.

20. Huang F, Cheng S, Du X, Chen W, Scano F, Falzon D, et al. Electronic recording and reporting system for tuberculosis in China: experience and opportunities. J Am Med Inform Assoc. 2014;21:938-41.

21. World Health Organization (WHO). Extensively DR tuberculosis (XDR.TB): recommendations for prevention and control. Wkly Epidemiol Rec. 2006;81: 430-2.

22. World Health Organization (WHO). Treatment guidelines for multidrug and rifampicin-resistant tuberculosis, 2018.

23. Wang Y, Zhang FM, Luo KW, Meng J. Regional and occupational distribution of 335 MDR-TB cases in Guizhou Province. J Guiyang Med College. 2012;37:302-3.

24. Pu J, Chen W, Jiang WX, Xing W, Liang SX, Li Y, et al. Is tuberculosis patients management improved in the integrated TB control model in West China? A survey in Guizhou Province, China. Infect Dis Poverty. 2018;81:55.

25. Hargreaves JR, Boccia D, Evans CA, Adato M, Petticrew M, Porter JD. The social determinants of tuberculosis: from evidence to action. Am J Public Health. 2011;101:654-62.

26. World Health Organization (WHO). Implementing the End TB Strategy: the essentials (WHO/HTM/TB/2015.31). Geneva; 2015. http://www.who.int/tb/ publications/2015/end tb essential.pdf?ua=1.

27. Wang $H$, Pan JP, Zhang $T H, A i X Q$, Han $Y L$, Wang WQ, et al. Survey on the knowledge, attitude and behaviors of TB among college students. Chin J Public Health. 2006;22:661-2.

28. Du X, Chen W, Huang F. Analysis on TB of national report of students TB during 2004-2008. Chin Health Educ. 2009;25:803-5.

29. Zhou S, Chen M. Epidemiology survey on outbreaks of TB in the universities in Chongqing. Health Med Res Pract Higher Inst. 2005;2:7-10.

30. Pang $Y$, Wu CG, Liu Y, Zhang T, Duan WX, Yu Y, et al. Analysis of the disposal of tuberculosis clusters in schools in Chongqing in 2017. Chin J Tropical Med. 2019;1:97-9.

31. Pang Y, Liu Y, Wang QY. An overview of the prevalence of tuberculosis epidemics in schools in Chongqing in 2016. Pract Prev Med. 2018;1:10-3.

32. Zhao Y, Ehiri J, Li D, Luo X, Ying L. A survey of TB knowledge among medical students in Southwest China: is the information reaching the target? BMJ Open. 2013;3:e003454.
33. Wang QY, Hu DY, Liu Y, Shen J. Chongqing City tuberculosis drug resistance analysis. Chongqing Med. 2014;22:2913-5.

34. Zhang W, Hu DY, Liu Y, Yu Y, Su Q, Zhang T. Prevalence of multidrugresistance in 638 tuberculosis patients in Chongqing. Chin J Tropical Med. 2017;17:231-5.

35. Yu HY, Zhang W, Lu RR, Wu GH, Su K, Zhang Y, et al. The epidemiological characteristics and long-term trend of HIV infection and AIDS in Chongqing from 1995 to 2015. J Third Mil Med Univ. 2017;20:2051-8.

36. World Health Organization (WHO). Global tuberculosis control report 2013. WHO/HTM/TB/2013.11.http://apps.who.int/iris/bitstream/10665/91355/1/ 9789241564656 eng.pdf.

37. Tsiouris SJ, Gandhi NR, El-Sadr WM, Friedland G. Tuberculosis and HIVneeded: a new paradigm for the control and management of linked epidemics. J Int AIDS Soc. 2007;9:62.

38. Havlir DV, Getahun H, Sanne I, Nunn P. Opportunities and challenges for HIV care in overlapping HIV and TB epidemics. JAMA. 2008;300:423-30.

39. Story A, Murad S, Roberts W, Verheyen M, Hayward AC. Tuberculosis in London: the importance of homelessness, problem drug use and prison. Thorax. 2007;62:667-71.

40. Dubrovina I, Miskinis K, Lyepshina S, Yann Y, Zignol M. DR tuberculosis and HIV in Ukraine: a threatening convergence of two epidemics? Int J Tuberc Lung Dis. 2008;12:756-62.

41. Wright A, Zignol M, Van Deun A, Falzon D, Gerdes S, Feldman K, et al. Epidemiology of antituberculosis drug resistance 2002-07: an updated analysis of the global project on anti-tuberculosis drug resistance surveillance. Lancet. 2009:373:1861-73.

42. Gandhi NR, Nunn P, Dheda K, Schaaf HS, Bayona J. Multidrug-resistant and extensively drug-resistant tuberculosis: a threat to global control of tuberculosis. Lancet. 2010;375:1830-43.

43. Shao Y, Yang D, Xu W, Lu W, Wang J. Epidemiology of anti-tuberculosis drug resistance in a chinese population: current situation and challenges ahead. BMC Public Health. 2011;11:110.

44. Pam OI, Noel O, Susan O, Florence M, Joshua N, Pere-Joan C. Prevalence of drug resistance Mycobacterium tuberculosis among patients seen in coast provincial general hospital, mombasa, kenya. PLoS One. 2016;11:e0163994.

45. Zhou Y. Analysis of risk factors of drug-induced liver injury induced by antituberculous therapy. Chin J Clin Ration Drug Use. 2018:11:54-5.

46. Hutchison C, Khan MS, Yoong J, Lin X, Coker RJ. Financial barriers and coping strategies: a qualitative study of accessing multidrug-resistant tuberculosis and tuberculosis care in Yunnan, China. BMC Public Health. 2017:17:221.

47. Bastard M, Sanchez-Padilla E, du Cros P, Khamraev AK, Parpieva N, Tillyashaykov M, et al. Outcomes of HIV-infected versus HIV-non infected patients treated for drug-resistance. tuberculosis: Multicenter cohort study. PLoS One. 2018;13:e0193491.

48. Mao SY, Xu SX. Comparative analysis of drug resistance of AIDS combined with tuberculosis and simple tuberculosis. Med Front. 2016;2:38.

49. Xia H. A molecular epidemiological study on HIV/AIDS patients of Han nationality from Chongqing. China: Third Military Medical University; 2009.

\section{Publisher's Note}

Springer Nature remains neutral with regard to jurisdictional claims in published maps and institutional affiliations.

Ready to submit your research? Choose BMC and benefit from

- fast, convenient online submission

- thorough peer review by experienced researchers in your field

- rapid publication on acceptance

- support for research data, including large and complex data types

- gold Open Access which fosters wider collaboration and increased citations

- maximum visibility for your research: over $100 \mathrm{M}$ website views per year

At $\mathrm{BMC}$, research is always in progress.

Learn more biomedcentral.com/submission 